\title{
2011s-32 \\ International Environmental Agreements in the Presence of Adaptation
}

\author{
Walid Marrouch, Amrita Ray Chaudhuri
}

Série Scientifique
Scientific Series

\section{Montréal}

Février 2011

(C) 2011 Walid Marrouch, Amrita Ray Chaudhuri. Tous droits réservés. All rights reserved. Reproduction partielle permise avec citation du document source, incluant la notice (C).

Short sections may be quoted without explicit permission, if full credit, including (C) notice, is given to the source.
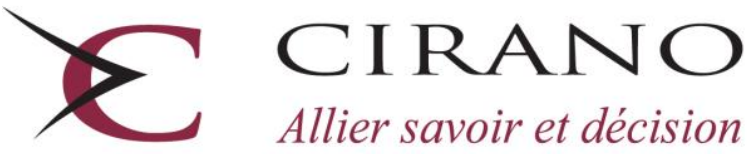

Allier savoir et décision

Centre interuniversitaire de recherche en analyse des organisations 


\section{CIRANO}

Le CIRANO est un organisme sans but lucratif constitué en vertu de la Loi des compagnies du Québec. Le financement de son infrastructure et de ses activités de recherche provient des cotisations de ses organisations-membres, d'une subvention d'infrastructure du Ministère du Développement économique et régional et de la Recherche, de même que des subventions et mandats obtenus par ses équipes de recherche.

CIRANO is a private non-profit organization incorporated under the Québec Companies Act. Its infrastructure and research activities are funded through fees paid by member organizations, an infrastructure grant from the Ministère du Développement économique et régional et de la Recherche, and grants and research mandates obtained by its research teams.

\section{Les partenaires du CIRANO}

Partenaire majeur

Ministère du Développement économique, de l'Innovation et de l'Exportation

\section{Partenaires corporatifs}

Banque de développement du Canada

Banque du Canada

Banque Laurentienne du Canada

Banque Nationale du Canada

Banque Royale du Canada

Banque Scotia

Bell Canada

BMO Groupe financier

Caisse de dépôt et placement du Québec

Fédération des caisses Desjardins du Québec

Financière Sun Life, Québec

Gaz Métro

Hydro-Québec

Industrie Canada

Investissements PSP

Ministère des Finances du Québec

Power Corporation du Canada

Raymond Chabot Grant Thornton

Rio Tinto

State Street Global Advisors

Transat A.T.

Ville de Montréal

\section{Partenaires universitaires}

École Polytechnique de Montréal

HEC Montréal

McGill University

Université Concordia

Université de Montréal

Université de Sherbrooke

Université du Québec

Université du Québec à Montréal

Université Laval

Le CIRANO collabore avec de nombreux centres et chaires de recherche universitaires dont on peut consulter la liste sur son site web.

Les cahiers de la série scientifique (CS) visent à rendre accessibles des résultats de recherche effectuée au CIRANO afin de susciter échanges et commentaires. Ces cahiers sont écrits dans le style des publications scientifiques. Les idées et les opinions émises sont sous l'unique responsabilité des auteurs et ne représentent pas nécessairement les positions du CIRANO ou de ses partenaires.

This paper presents research carried out at CIRANO and aims at encouraging discussion and comment. The observations and viewpoints expressed are the sole responsibility of the authors. They do not necessarily represent positions of CIRANO or its partners. 


\title{
International Environmental Agreements in the Presence of Adaptation
}

\author{
Walid Marrouch ${ }^{\dagger}$,Amrita Ray Chaudhurit
}

\begin{abstract}
Résumé / Abstract
Nous montrons que les mesures d'adaptation aux changements climatiques vont réduire directement les dommages causés par les changements climatiques. En plus, ces mesures peuvent aussi, indirectement, réduire les émissions des gaz à effet de serre puisqu'ils vont augmenter le nombre des participants dans les accords internationaux sur la réduction des émissions. En outre, nous montrons que la taille stable des accords internationaux sur l'environnement augmente avec l'efficacité des mesures d'adaptation. Par ailleurs, nous établissons que les grandes coalitions peuvent mener à des niveaux inférieurs d'émissions globales, et en plus ces grandes coalitions augment le bien-être mondial.
\end{abstract}

Mots clés : accords environnementaux internationaux, adaptation, formation de coalitions, changements climatiques.

We show that adaptive measures undertaken by countries in the face of climate change, apart from directly reducing the damage caused by climate change, may also indirectly mitigate greenhouse gas emissions by increasing the stable size of international agreements on emission reductions. Moreover, we show that the more effective the adaptive measure in terms of reducing the marginal damage from emissions, the larger the stable size of the international environmental agreement. In addition, we show that larger coalitions may lead to lower global emission levels and higher welfare.

Keywords: international environmental agreements, adaptation, coalition formation, climate change.

Codes JEL: Q54, Q59

\footnotetext{
* We are grateful for insightful comments from seminar participants at GERAD and at the Montreal Resource and Environmental Economics Workshop.

${ }^{\dagger}$ Lebanese American University, School of Business, Department of Economics and Finance, Beirut, Lebanon, P.O. Box 13-5053 / F-15, New York Office 475 Riverside Drive, Suite 1846 New York, NY 10115-0065-USA, Email: walid.marrouch@lau.edu.lb. CIRANO (Center for Interuniversity Research and Analysis on Organizations), 2020, University St., 25th Floor, Montreal, QC, Canada, H3A 2A5.

* Department of Economics, CentER, TILEC, Tilburg University, Warandelaan 2, P.O. Box 90153, 5000 LE Tilburg, The Netherlands, E-mail: a.raychaudhuri@uvt.nl. Department of Economics, The University of Winnipeg, 515 Portage Avenue, Winnipeg, MB, Canada R3B 2E9.
} 


\section{Introduction}

Countries around the world are currently actively pursuing two different means of tackling climate change. First, countries are attempting to mitigate emissions of greenhouse gases (GHGs) through international negotiations. Second, countries are undertaking adaptive measures to reduce the negative effects of climate change. The purpose of this paper is to investigate whether the success of the first, in fact, depends on the latter. That is, does adaptation affect the stable size of international environmental agreements (IEAs)?

An individual country's emissions of GHGs causes a negative externality on other countries by exacerbating climate change. A country choosing its emission level non-cooperatively (i.e. maximizing its individual welfare) would, therefore, over-pollute relative to the cooperative outcome (where each country maximizes joint welfare of all countries when choosing its emission level). International cooperation to set emission levels has, thus, been a natural approach to alleviating climate change. However, some have argued that mitigation of greenhouse gas emissions cannot be the only policy response to climate change because due to the inertia of the climate system, even drastic emission reduction targets today would not be sufficient to slow down global climate change. This has resulted, in recent years, in countries increasingly undertaking adaptive measures to reduce the potential damage caused by climate change induced catastrophes such as floods. A recent article in The Economist, entitled "How to live with climate change: It won't be stopped, but its effects can be made less bad", captures the ongoing developments as follows "... in the wake of the Copenhagen summit, there is a growing acceptance that the effort to avert serious climate change has run out of steam... Acceptance, however, does not mean inaction. Since the beginning of time, creatures have adapted to changes in their environment..."

The term "adaptation", within this context, refers to adjustments in ecological, social or economic systems for reducing potential damage from climate change (Parry et al, 2007). It is loosely defined to cover a wide range of measures including the building of dykes or levees, the changing of crop types and facilitating early storm warning. 
This paper asks whether such adaptive measures undertaken by countries increase or decrease the number of countries that participate in a stable self-enforcing international environmental agreement. Given that adaptation reduces the marginal damage from pollution, countries within and outside the IEA have an incentive to emit more in the presence of adaptation. This leads to the next question addressed by the paper. Are IEAs, for any given coalition size, as effective in reducing global emissions as in the absence of adaptation? Or does adaptation reduce the desirability of IEAs from the perspective of social welfare?

These questions gain importance in light of the persistent failure of countries to reach binding commitments on emission targets, as embodied at the UN Climate Conferences held in Kyoto in 1997 and Copenhagen in 2009, and the billions of dollars that governments are setting aside for developing adaptive measures to safeguard against imminent damage from climate change. Since adaptation generates public goods, we observe heavy intervention by national governments and international organizations in the provision of adaptive measures. Since 1980, the World Bank has approved more than 500 operations related to disaster management, amounting to more than US $\$ 40$ billion. Estimates provided by international organizations of financial resources needed in developing countries for adaptation include: $\$ 10$ to $\$ 40$ billion annually (World Bank, 2007), $\$ 50$ billion annually (Oxfam International, 2007), $\$ 86$ billion annually by 2015 (UNDP, 2007), $\$ 46$ to $\$ 171$ billion annually by 2030 (UNFCCC, 2007). Moreover, there exist several adaptation funds run by the UNFCCC, World Bank and European Commission that have already contributed in the millions towards adaptation. ${ }^{1}$

The existing literature on adaptation can be broadly categorized into two streams. The

\footnotetext{
${ }^{1}$ According to Le Goulven (2008), existing adaptation funds inlcude the following. The UNFCCC pledged $\$ 50$ million through the SPA (Strategic Priority "Piloting an Operational Approach to Adaptation") in 2001 of which $\$ 28$ million had been committed and $\$ 14.8$ million disbursed by 2008 . The UNFCCC pledged $\$ 165$ million through the LDCF (Least Developed Countries Fund) in 2001 of which $\$ 59$ million had been committed and $\$ 9.8$ million spent by 2008 . The UNFCCC pledged $\$ 65$ million through the SCCF (Special Climate Change Fund) in 2001 of which $\$ 9$ million had been committed and $\$ 1.4$ million spent by 2008 . Also in 2001, the Kyoto Protocol set up an Adaptation Fund which pledged $\$ 160-950$ million by 2012 . In 2008, the World Bank's Pilot Program for Climate Resilience under the Strategic Climate Fund pledged $\$ 500$ million. In 2007, the European Commission pledged EUR 50 million under the Global Climate Change Alliance and the German Ministry of the Environment pledged EUR 60 million.
} 
first provides a description of the tradeoff facing countries when deciding how to allocate resources between mitigating GHG emissions and adapting to climate change (see for example, Auerswald, Konrad and Thum (2011), Buob and Stephan, 2009; Klein, Schipper, and Dessai, 2003 and 2005; Kane and Shogren, 2000; Kane and Yohe, 2000; Ingham, Ma, and Ulph, 2005; McKibbin and Wilcoxen, 2003; Tol, 2005). The second stream explicitly incorporates adaptation in integrated assessment models to analyze the interaction between mitigation and adaptation (see for example Bosello, 2004; De Bruin, Dellink, and Agrawala, 2009; De Bruin, Dellink, and Tol, 2009). Other integrated assessment models such as MERGE (Manne, Mendelsohn, and Richels, 1995), and RICE (Nordhaus and Yang, 1996) implicitly capture adaptation by incorporating the costs of adaptation in the regional damage function. But none of these papers allow for coalition formation amongst the countries and therefore, do not analyze the impact of adaptation on the stability of international environmental agreements.

There also exists an established literature on the sustainability of international agreements on emission reductions (including Barrett, 1994 and 2003; Breton, Sbragia and Zaccour, 2010; Breton et al, 2009; Carraro and Siniscalco, 1993; Chander and Tulkens, 1995 and 1997; Diamantoudi and Sartzetakis, 2006; Tulkens and Eyckmans, 1999; Finus and Rundshagen, 2001 and 2003; Hoel and Schneider, 1997; Petrosjan and Zaccour, 2003; Rubio and Ulph, 2006 and 2007; de Zeeuw, 2008). However, these papers do not allow for countries to engage in adaptation.

This paper intends to bridge the gap between these two streams of the existing literature by setting up a game theoretic framework, which incorporates both adaptation and joining an IEA as strategies available to countries dealing with climate change.

We use a membership game similar to Barrett $(1994,2003)$ to model international environmental agreements. The stability concept used is à la d'Aspremont et al. (1983) which defines stability in terms of immunity to unilateral deviations. This can be achieved only when the coalition is internally stable with no country having an incentive to withdraw, 
and externally stable with no country having an incentive to further participate. Moreover, we assume that the effect of adaptation is local whereas the damage caused by emissions is global, in line with real examples of adaptive measures currently being undertaken by different countries. Our main contribution is to show that allowing for countries to engage in costly adaptation activities increases the stable coalition size that is formed within this framework. This is in sharp contrast to the findings of much of the existing IEA literature which concludes that only very small coalitions are stable (see for example, Barrett, 1994 and 2003; Diamantoudi and Sartzetakis, 2006). This paper provides a more positive result by illustrating that if the countries involved negotiate not only on emission targets but also on the level of adaptation, then it is possible to attract a greater number of countries to commit to emission and adaptation levels that maximize the joint welfare of the coalition members rather than individual welfare. The natural question that arises is whether such IEAs, in the presence of adaptation, lead to greater or less emissions at the global level. The answer is a priori ambiguous since, on the one hand, adaptation, by reducing marginal damage from emissions, induces both countries within and outside the IEA to emit more. On the other hand, since adaptation is a costly activity (see footnote 1), countries have an incentive to jointly emit less to avoid these costs.

This leads to our second contribution which is to show that, within this context, larger coalitions may lead to lower levels of total emissions and reduce total emissions below the non-cooperative level, so that adaptation ultimately helps in two ways (i) first by directly reducing the damage from climate change and (ii) second by indirectly causing countries to mitigate emissions by reaching a larger stable IEA. This is again in contrast to the existing IEA literature which does not account for adaptation and concludes that large coalitions, even when stable, are typically "shallow", that is, they lead to more emissions than at the non-cooperative equilibrium (Barrett, 1994 and 2003; Finus and Rundshagen, 2003). Thus, adaptation, rather than merely being a substitute for the failed attempts at negotiating an IEA, as suggested currently in The Economist (November 2010) and other media outlets, 
may actually foster international cooperation on mitigating emissions of GHGs. ${ }^{2}$ However, we prescribe caution when interpreting this result since the possibility that a larger coalition size leads to a shallow agreement is not completely excluded within our framework. Instead, what we show is that by carefully choosing the "type" of adaptive measures undertaken, it is possible for countries to achieve large coalitions that are not shallow.

Our results depend crucially on the type of adaptation used by countries. In particular, our positive results only hold when the adaptive measure is able to significantly reduce the marginal damage from emissions. In reality, the different adaptive measures undertaken by regions differ significantly in their ability to reduce marginal damage from emissions. ${ }^{3}$ On one extreme, consider carbon sequestration which simply reduces the amount of GHGs in the atmosphere without affecting the marginal damage from emissions. On the other hand, consider a levee which protects a coastal region repeatedly from an increasing onset of floods caused by climate change. The latter clearly reduces the marginal damage of emissions. In our model, the degree to which adaptation is able to reduce marginal damage from emissions is captured by the parameter $\theta$. Thus, carbon sequestration would have $\theta=0$ whilst the levee would be associated with a $\theta>0$. An alternative interpretation of $\theta$ is the following. Some adaptive measures require a high cost of implementation post-disaster whilst others avoid this cost to society by preventing the disaster from occurring. The former type of adaptation is represented, in this paper, by a low $\theta$ and the latter by a high $\theta$. According to the Red Cross Climate Centre, every $\$ 1$ invested before a disaster saves $\$ 4$ afterwards. Examples of the former, also known as reactive disaster management measures, include post-disaster reconstruction projects such as reconstruction of physical infrastructure and flood evacuation

\footnotetext{
${ }^{2}$ Indeed, it seems that countries are realizing the importance of including adaptation in international negotiations, given the new "Cancun Adaptation Fund" that has been established at the COP16 Meetings held at Cancun in December 2010. (UNFCCC Press Release, 11 December 2011, http://unfccc.int/files/press/news_room/press_releases_and_advisories/application/pdf/ pr_20101211_cop16_closing.pdf)

${ }^{3}$ For specific examples, the reader may refer to the material presented at the Workshop on "The State of International Climate Finance: Is it adequate and is it productive?", organized by the International Center for Climate Governance, held in Venice, October 2010.
} 
schemes. ${ }^{4}$ Examples of the latter, also known as proactive disaster management measures, include prevention measures, such as early warning measures and developing methods for accurate risk assessments ${ }^{5}$, education campaigns, improvement of irrigation facilities in rural areas, zoning, flood prevention mechanisms ranging from shore protection (building levees) and terracing in rural areas ${ }^{6}$ to adaptation of production, and sound urban planning. ${ }^{7}$

Given the wide variety of adaptive measures that countries can choose to invest in, this paper effectively provides a selection criterion. It emphasizes that countries benefit more by choosing those types of adaptive measures that reduce marginal damage from emissions the most (i.e. those associated with a high $\theta$ ). Implementing this type of adaptive measures results in larger stable IEAs which mitigate emissions. This is an important result since, according to The Economist, 27 November 2010, as much as two-thirds of the damage from climate change in terms of higher prices and lower growth worldwide cannot be offset through investment in adaptation alone. Therefore, it is a particularly desirable property of adaptation that it can induce more mitigation of emissions of GHGs, under the right

\footnotetext{
${ }^{4}$ The World Bank has implemeted post-disaster reconstruction projects in Argentina (e.g. The Argentina Flood Rehabilitation Project), Brazil (e.g. The Rio Flood Reconstruction Prevention Project), Mexico and India (e.g. Maharashtra Emergency Earthquake Rehabilitation Program). See Ranghieri (2010) for further details.

${ }^{5}$ Example of early warning programs include The Early Warning System for Hydrogeological Risk Monitoring and Forecast of Calabria Region (Italy) and the National Forecast Center (Cuba). The United Nations International Strategy for Disaster Reduction includes The Hyogo Framework for Action (HFA) monitoring tools for disaster risk reduction in the Europe region (http://www.preventionweb.net/english/hyogo/hfamonitoring/).

The EU has its own program MOVE: Methods for the Improvement of Vulnerability Assessment in Europe. The UFZ - CapHaz-Net, RiskMap \& ConHaz: Natural Hazards Management Projects in Germany has similar objectives. There also exists the Capacity Building Program through DIANE-CM (Decentralised Integrated Analysis and Enhancement of Awareness through Collaborative Modelling and Management of Flood Risk) which aims to Integrate, Consolidate and Disseminate European Flood Risk Management Research.

${ }^{6}$ Examples include proactive projects such as Coastal environmental preservation - mangrove planting: Vietnam Red Cross, Focus on response preparedness: Bangladesh Red Crescent Society and FREEMAN: Flood REsilience Enhancement and MANagement: a pilot study in Flanders, Germany and Italy.

${ }^{7}$ At the Mayors' Summit in Copenhagen (December 2009), the Mayors' Task Force on Urban Poverty and Climate Change was formed and is actively helping cities like Dar es Salaam, Jakarta, Mexico City and Sao Paulo (see Ranghieri (2010)). National and regional governments also have set up several intititutes to prevent disasters such as the All India Disaster Mitigation Institute, and the ENSURE Program of the EU for enhancing resilience of communities and territories facing natural hazards.
} 
conditions.

The paper proceeds as follows. In Section 2, we present the model. Section 3 presents the membership game used to analyze coalition formation. Section 4 presents the effect of allowing for adaptation on the outcome of the game. Section 5 concludes.

\section{The Model}

Consider $n$ countries indexed by $i=1, . ., n$, where $N$ denotes the set of all countries. A by-product of the consumption and production activities of each country is the emission of a global pollutant. Country $i$ emits $e_{i} \geq 0$ units of the pollutant with the aggregate emissions denoted by $E=\sum_{i=1}^{n} e_{i}$. Each country is also allowed to spend resources on adapting to the damage from pollution. The level of adaptation chosen by country $i$ is given by $a_{i}$, and, in line with reality, is assumed to protect country $i$ only from the effects of climate change.

Social welfare of each country is assumed to be given by the following.

$$
w\left(E, a_{i}\right) \equiv B\left(e_{i}\right)-D\left(E, a_{i}\right)-C\left(a_{i}\right)
$$

In (1), $B\left(e_{i}\right)$ represents the benefit to country $i$ from its own emissions and is given by

$$
B\left(e_{i}\right) \equiv e_{i}\left(\alpha-\beta \frac{e_{i}}{2}\right)
$$

with $\alpha>0$ and $\beta>0$. That is, $B^{\prime}\left(e_{i}\right)>0$ and $B^{\prime \prime}\left(e_{i}\right)<0$.

In $(1), D\left(E, a_{i}\right)$ represents the damage to country $i$ from pollution and is given by

$$
D\left(E, a_{i}\right) \equiv\left(\omega E-\gamma a_{i}-\theta a_{i} E\right)
$$

with $\omega>0, \gamma \geq 0$ and $\theta \geq 0 .{ }^{8}$ From (3), the marginal damage from emissions is given by

\footnotetext{
${ }^{8}$ The tradeoff, in our damage function, between the levels of emission, $E$, and adaptation, $a_{i}$, is similar to that in the literature on multiple pollutants in the context of climate change, where some pollutants such
} 
$\frac{\partial D\left(E, a_{i}\right)}{\partial E}=\omega-\theta a_{i}$, which is decreasing in $\theta$. We also have that $\frac{\partial D\left(E, a_{i}\right)}{\partial a_{i}}=-(\gamma+\theta E)<0$, that is, pollution damage of country $i$ is decreasing in the level of country $\imath$ 's adaptation. From $(3)$, it also follows that $\frac{\partial^{2} D\left(E, a_{i}\right)}{\partial E \partial a_{i}}=\frac{\partial^{2} D\left(E, a_{i}\right)}{\partial a_{i} \partial E}=-\theta .^{9}$

Henceforth in the paper, we distinguish between the "level" of adaptation, as denoted by $a_{i}$, and the "type" of adaptation, as denoted by $\theta$. Here a high (low) $\theta$ refers to those "types" of adaptive measures that lead to a large (small) reduction in the marginal damage of emissions. For example, consider two different adaptive measures intended to protect coastal regions from the effects of flooding caused by climate change: a flood evacuation plan and the construction of levees. A flood evacuation plan has a low $\theta$ and building levees has a high $\theta$. If an extra levee is built, each extra unit of emission is less damaging than if an evacuation plan is put in place. Equivalently, for $\theta>0$, the marginal benefit of adaptation is increasing in the level of aggregate emissions. That is, the benefits to country $i$ from having an extra levee (i.e. a higher $a_{i}$ ) is greater the higher is $E$ since the levee serves to protect the country from a greater number of floods at a higher $E$.

In (1), $C\left(a_{i}\right)$ represents the cost of adaptation of country $i$ and is given by:

$$
C\left(a_{i}\right) \equiv \frac{c}{2} a_{i}^{2}
$$

We note that the cost of adaptation is strictly convex and increasing in $a_{i}$.

Given this setting, we consider two possible scenarios. The first scenario is one where the countries behave non-cooperatively. The objective of each country's government is to simultaneously choose $e_{i}$ and $a_{i}$ that maximize its own welfare taking as given the emissions as $\mathrm{CO}_{2}$ increase global warming and others such as $\mathrm{SO}_{2}$ have a cooling effect (see, for example, Legras and Zaccour (forthcoming)).

${ }^{9}$ In our model, the net cost of adaptation is given by the cost function, $C\left(a_{i}\right)$, less the benefit from adaptation in terms of reduced damage, $\gamma a_{i}+\theta a_{i} E$. Thus, our net cost of adaptation is decreasing in the global emission level, $E$, for all $\theta>0$. This is analogous to the way in which cost of R\&D has been modeled by Hoel and de Zeeuw (2010) within the context of international cooperation on the development of clean technologies, where the cost of $\mathrm{R} \& \mathrm{D}$ is decreasing in the level of $\mathrm{R} \& \mathrm{D}$. 
and adaptation strategies of the other countries. That is,

$$
\max _{e_{i}, a_{i}} w\left(E, a_{i}\right)
$$

where $w\left(E, a_{i}\right)$ is given by $(1)$.

The second scenario is one where the countries simultaneously choose $e_{i}$ and $a_{i}$ that maximize joint welfare. That is,

$$
\max _{e_{i}, a_{i}} \sum_{i=1}^{n} w\left(E, a_{i}\right)
$$

Henceforth, we make the following assumption.

Assumption 1: We have that $c \beta-\theta>0$.

Assumption 1 ensures that the cost of adaptation is sufficiently high such that the optimization problem facing each country in either scenario, as given by (4) and (5), becomes non-trivial within our framework.

\section{The Noncooperative Equilibrium}

In the noncooperative case, we maximize (4) with respect to $e_{i}$ and $a_{i}$. From these we obtain country $\imath$ 's emission reaction function, as given by the following:

$$
e_{i}=\frac{(\alpha-\omega) c+\theta \gamma+\theta^{2} \sum_{j \neq i}^{n} e_{j}}{c \beta-\theta^{2}}
$$

Lemma 1: For $c \beta>\theta^{2}$, the emission strategies of countries are strategic complements, that is, $e_{i}$ is increasing in $e_{j}, j \neq i$.

Lemma 1 follows directly from (6), and is in contrast to the standard result in the existing IEA literature ${ }^{10}$ and much of the literature on noncooperative games of transboundary pollution, where the emission strategies of countries are strategic substitutes. Thus, the presence of adaptation may overturn a well-established result. In the absence of adaptation,

\footnotetext{
${ }^{10}$ See for example Barrett (1994), Diamantoudi and Sartzetakis (2006).
} 
the only means available to country $i$ of reducing damage in response to an increase in other countries' emissions is to decrease its own emissions. And thus, the emission strategies of countries are strategic substitutes in the absence of adaptation. In this paper, we allow for two alternate possibilities that country $i$ can use to reduce its own damage when faced with an increase in other countries' emissions: either it can reduce its own emissions or it can increase its level of adaptation. If country $i$ chooses the latter option, it is possible that country $i$ simultaneously finds it optimal to emit more in reaction to the increase in other countries' emissions.

Since the countries are identical, in the noncooperative equilibrium, each country chooses emissions and adaptation given by:

$$
\begin{gathered}
e_{n c}=\frac{\theta \gamma+c(\alpha-\omega)}{c \beta-n \theta^{2}} \\
a_{n c}=\frac{\beta \gamma+n \theta(\alpha-\omega)}{c \beta-n \theta^{2}}
\end{gathered}
$$

The second order condition is satisfied since we have $\frac{\partial^{2} w}{\partial e_{i}^{2}}=-\beta<0, \frac{\partial^{2} w}{\partial a_{i}^{2}}=-c<0$ and $\left(\frac{\partial^{2} w}{\partial e_{i}^{2}}\right)\left(\frac{\partial^{2} w}{\partial a_{i}^{2}}\right)-\left(\frac{\partial^{2} w}{\partial a_{i} \partial e_{i}}\right)=(-\beta)(-c)-\theta$ which is positive under Assumption 1.

The equilibrium level of emissions of each country, $e_{n c}$, is increasing in $\alpha$ since, from (2) it follows that each unit of emission yields higher benefits at higher levels of $\alpha$. The equilibrium level of emissions of each country is decreasing in $\omega$ since each unit of emission generates more damage at the margin the higher is $\omega$. Since the equilibrium level of emissions of each country is lower at higher levels of $\omega$, it follows that equilibrium adaptation, $a_{n c}$, is also lower at higher levels of $\omega$, as long as adaptation is sufficiently costly (i.e. $c \beta-n \theta^{2}>0$ ), as shown by (8). This explains the a priori counter-intuitive effect of $\omega$ on $a_{n c}$, that is, the noncooperative adaptation level is decreasing in $\omega$.

We note that both $e_{n c}$ and $a_{n c}$ are increasing in $\theta$. The intuition for this is the following. For higher values of $\theta$, at the margin, adaptation leads to greater reductions in the marginal damage from emissions. Therefore, countries have an incentive to adapt more. Also, by 
adapting more, countries can emit more, since each unit of emission is now less damaging.

\section{Full Cooperation}

In the cooperative equilibrium, each country chooses emissions and adaptation to maximize

(5) and these values are given by:

$$
\begin{aligned}
& e_{c}=\frac{n \theta \gamma+c(\alpha-n \omega)}{c \beta-n^{2} \theta^{2}} \\
& a_{c}=\frac{\beta \gamma+n \theta(\alpha-n \omega)}{c \beta-n^{2} \theta^{2}}
\end{aligned}
$$

We note that both $e_{c}$ and $a_{c}$ are also increasing in $\theta$, similar to the result for $e_{n c}$ and $a_{n c}$.

The second order condition is satisfied since we have $\frac{\partial^{2} w}{\partial e_{i}^{2}}=-n \beta<0, \frac{\partial^{2} w}{\partial a_{i}^{2}}=-n c<0$ and $\left(\frac{\partial^{2} w}{\partial e_{i}^{2}}\right)\left(\frac{\partial^{2} w}{\partial a_{i}^{2}}\right)-\left(\frac{\partial^{2} w}{\partial a_{i} \partial e_{i}}\right)=(-n \beta)(-n c)-n^{2} \theta$ which is positive under Assumption 1 .

Furthermore, we have that $\left(e_{n c}-e_{c}\right)$ and $\left(a_{n c}-a_{c}\right)$ are given by

$$
e_{n c}-e_{c}=c(n-1) \frac{c \beta \omega-\theta \beta \gamma-n \theta^{2} \alpha}{\left(c \beta-n^{2} \theta^{2}\right)\left(c \beta-n \theta^{2}\right)}
$$

and

$$
a_{n c}-a_{c}=n \theta(n-1) \frac{c \beta \omega-\theta \beta \gamma-n \theta^{2} \alpha}{\left(c \beta-n^{2} \theta^{2}\right)\left(c \beta-n \theta^{2}\right)}
$$

These are of the same sign, signifying that if adaptation is higher in one of the scenarios, so are emissions. Moreover, it is possible that we get a dismal result whereby countries emit more under full cooperation than under the non-cooperative equilibrium. This occurs if the cost of adaptation, $c$, is sufficiently low, such that joint welfare is maximized if countries emit more than under non-cooperation and simply adapt to the resulting damages.

For the extreme case where $\gamma=\theta=0$, we retrieve the game without any adaptation. ${ }^{11}$ In this case, the equilibrium emissions under non-cooperative equilibrium are higher than under the cooperative equilibrium due to the standard free-riding effect, with $e_{n c}-e_{c}=$ $\frac{(n-1) \omega}{\beta}>0$.

\footnotetext{
${ }^{11}$ See for example, Diamantoudi and Sartzetakis (2006) and others.
} 


\section{Coalition formation}

Consider the scenario where the countries decide to form an international environmental agreement. More specifically, let $S \subset N$ countries sign an agreement while $N \backslash S$ do not. We denote the size of coalition $S$ by $s$ and the total emission generated by the coalition by $E_{s}=s e_{s}$, where $e_{s}$ is the emission of a representative signatory. Similarly, $E_{n s}=(n-s) e_{n s}$ is the total emissions generated by the complement of the coalition with $e_{n s}$ being the emissions generated by a representative non-signatory. The sum of the emissions of the signatory and non-signatory countries, that is global emissions, is given by $E=E_{s}+E_{n s}$.

Following Barrett (1994), we assume that the nonsignatories behave noncooperatively after observing the emission and adaptation choices of the signatories. The nonsignatories' maximization problem is given by (4) which results in the following best response function:

$$
e_{i}=\frac{(\alpha-\omega) c+\theta \gamma+\theta^{2}\left(\sum_{j \neq i}^{n-s} e_{j}+\sum_{k}^{s} e_{k}\right)}{\beta c-\theta^{2}}, i \in N \backslash S, k \in S
$$

By symmetry, from (11) we have that the best response of a non-signatory is given by:

$$
e_{n s}\left(e_{s}\right)=\frac{(\alpha-\omega) c+\theta \gamma+\theta^{2}\left(s e_{s}\right)}{\beta c-\theta^{2}(n-s)}
$$

The non-signatories' adaptation strategies are given by:

$$
a_{i}=\frac{\gamma+\theta\left(\sum_{i}^{n-s} e_{i}+\sum_{k}^{s} e_{k}\right)}{c}, i \in N \backslash S, k \in S
$$

By symmetry, we have that the level of adaptation of each non-signatory country is given by:

$$
a_{n s}\left(e_{s}\right)=\frac{\gamma+\theta\left((n-s) e_{n s}\left(e_{s}\right)+s e_{s}\right)}{c}
$$

The signatories choose their emission and adaptation levels by maximizing their joint welfare while taking into account the behavior of nonsignatories, as given by $e_{n s}\left(e_{s}\right)$ and 
$a_{n s}\left(e_{s}\right)$. That is, signatories choose $e_{s}$ and $a_{s}$ by solving the following maximization problem.

$$
\max _{e_{s}, a_{s}} s\left[B\left(e_{s}\right)-D\left[(n-s) e_{n s}\left(e_{s}\right)+s e_{s}, a_{s}\right]-C\left(a_{s}\right)\right]
$$

Henceforth, for analytical tractability, we normalize the following parameter values such that $n=100, \alpha=\beta=c=1$. Given these parameter values, we restrict our attention to values of $\theta$ that satisfy Assumption 1 and the condition that $c \beta>\theta^{2}$ such that by Lemma 1, the emissions strategies of countries are strategic complements. We have checked that the following results hold for several other numerical examples that we have considered that also satisfy these conditions.

Given that the signatory countries maximize (15), and given the best response functions of the non-signatory countries as given by (12) and (14), we can derive the equilibrium values of emission and adaptation levels denoted by $e_{s}^{*}, a_{s}^{*}, e_{n s}^{*}$ and $a_{n s}^{*}$ which are functions of the parameters $s, \theta, \gamma$ and $\omega .{ }^{12}$ We note that if $s=n$, we revert to the full cooperative case, that is, $\left.e_{s}^{*}\right|_{s=n}=e_{c}$ and $\left.a_{s}^{*}\right|_{s=n}=a_{c}$. When $s=0$, we revert to the non-cooperative case, such that $\left.a_{n s}^{*}\right|_{s=0}=a_{n c}$ and $\left.e_{n s}^{*}\right|_{s=0}=e_{n c}$.

The equilibrium global emissions, that is, the sum of emissions of all countries is given by $E^{*}=s e_{s}^{*}+(n-s) e_{n s}^{*}$. Also, the change in global emissions due to the formation of a coalition of size $s$ is given by $\Delta E=E^{*}-100 e_{n c}^{*}{ }^{13}$

The welfare of each signatory country, at the equilibrium, is given by:

$$
w_{s}^{*} \equiv e_{s}^{*}\left(\alpha-\beta \frac{e_{s}^{*}}{2}\right)-\left(\omega E^{*}-\gamma a_{s}^{*}-\theta a_{s}^{*} E^{*}\right)-\frac{c}{2} a_{s}^{* 2}
$$

\footnotetext{
${ }^{12}$ For the complete functional forms please refer to A1-A4 in the Appendix.

${ }^{13}$ For the complete functional forms please refer to A5-A6 in the Appendix.
} 
The welfare of each non-signatory country, at the equilibrium, is given by:

$$
w_{n s}^{*} \equiv e_{n s}^{*}\left(\alpha-\beta \frac{e_{n s}^{*}}{2}\right)-\left(\omega E^{*}-\gamma a_{n s}^{*}-\theta a_{n s}^{*} E^{*}\right)-\frac{c}{2} a_{n s}^{* 2} .
$$

The equilibrium global welfare, that is, the sum of welfare of all countries is given by:

$$
W^{*}=s w_{s}^{*}+(n-s) w_{n s}^{*} .
$$

\subsection{Stability function}

In order to compute the stable size of the coalition we use the stability concept as presented by d'Aspremont et al. (1983), where a coalition is stable if it is both internally and externally stable. Formally, internal stability implies that: $w_{s}^{*}(s) \geq w_{n s}^{*}(s-1)$ for all $i \in S$ i.e. there is no incentive for any one member to leave the coalition, where $w_{s}^{*}(s)$ is defined by (16) and $w_{n s}^{*}(s-1)$ is derived from (17) by replacing $s$ by $(s-1)$. External stability implies that $w_{n s}^{*}(s) \geq w_{s}^{*}(s+1)$ for all $i \in N \backslash S$, i.e. there are no further incentives for any non-member to join the coalition, where $w_{n s}^{*}(s)$ is defined by (17) and $w_{s}^{*}(s+1)$ is derived from (16) by replacing $s$ by $s+1$. For the purpose of our analysis, it is useful to define the stability function as in Hoel and Schneider (1997), which is represented by the following:

$$
\Phi_{i}(s)=w_{s}^{*}(s)-w_{n s}^{*}(s-1) .
$$

Internal stability of a coalition of size $s$ implies that

$$
\Phi_{i}(s) \geq 0 \quad \forall i \in S
$$

and external stability of a coalition of size $s$ implies that

$$
\Phi_{i}(s+1)<0 \quad \forall i \in N \backslash S .
$$


We say that $s^{*}$ is the stable size of the coalition $S$ if $s^{*}$ satisfies both (19) and (20) simultaneously. This implies that $s^{*}$ is the largest integer equal to or smaller than the value at which the stability function $\Phi$ becomes null and is decreasing around this value.

\section{IEAs in the presence of adaptation}

We proceed to examine the stability function for different values of $\theta$. We begin with the benchmark case where $\theta=0$ and then analyze the case where $\theta$ is strictly positive.

Proposition 1: For $\theta=0$ and for all $\gamma \geq 0$, the stable size of the coalition is given by $s^{*}=3$.

Proof: When $\theta=0$ and for all $\gamma \geq 0$ the stability function, (18), reduces to the following:

$$
\left.\Phi_{i}(s)\right|_{\theta=0}=\frac{1}{2} \omega^{2}\left(4 s-s^{2}-3\right)
$$

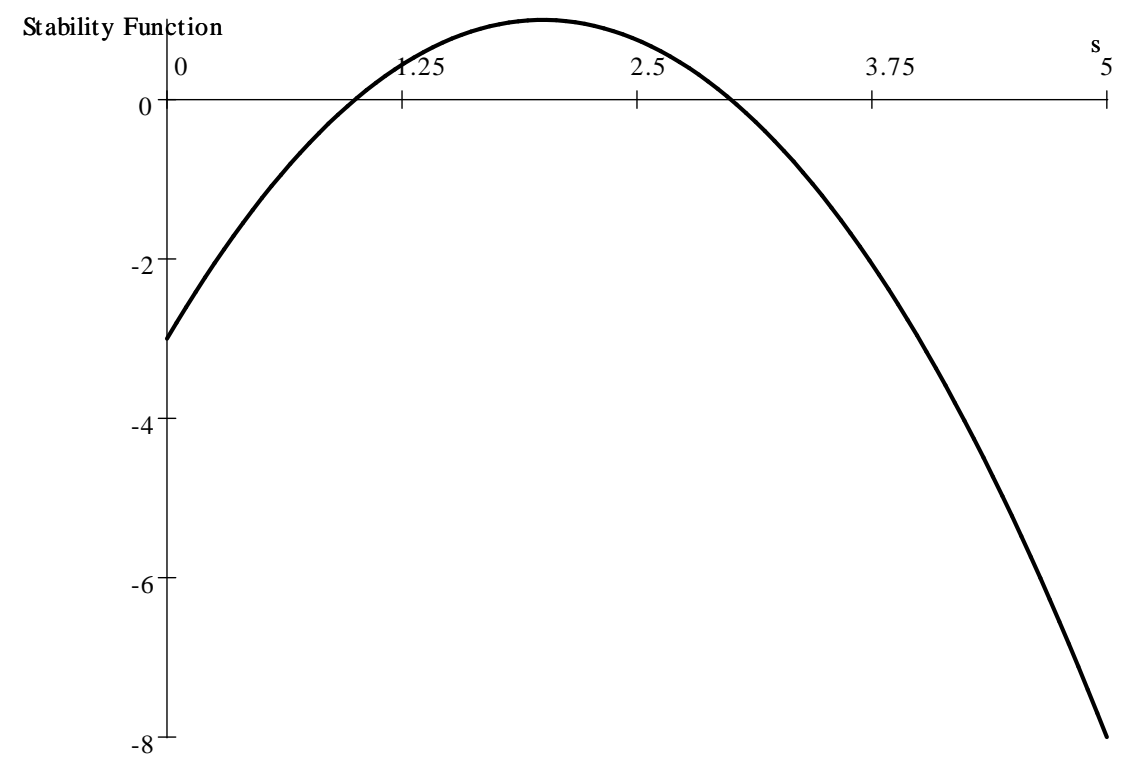

Figure 1. Stability function at $\theta=0$.

Proposition 1 follows directly from (21)

As per Proposition 1, we revert to the 'puzzle of small coalitions' found in the literature on environmental membership games where it is indicated that the stable size is between 2 
and 4 as is the case in Carraro and Siniscalco (1993), De Cara and Rotillon (2001), Finus and Rundshagen (2001), and Rubio and Casino (2001) among others. Proposition 1 consists of the two following cases.

\subsection{Case 1: No adaptation $(\theta=0$ and $\gamma=0)$}

The scenario where $\theta=0$ and $\gamma=0$ represents the benchmark case where countries do not adapt in any scenario, i.e. $a_{s}^{*}=a_{n s}^{*}=a_{n c}^{*}=a_{c}^{*}=0$, since adaptation is completely ineffective in reducing pollution damage.

\subsection{Case 2: Adaptation without interaction $(\theta=0$ and $\gamma>0)$}

When $\theta=0$, then there is no interaction in the damage function between emissions and adaptation. This, together with $\gamma>0$ implies that adapation becomes equivalent to negative emissions in the damage function. An example of this is carbon sequestration.

In this case, the equilibrium level of adaptation is equal to the marginal efficiency of adaptation in reducing pollution damage in all scenarios (that is, regardless of coalition formation) as shown below.

$$
a_{s}^{*}=a_{n s}^{*}=a_{n c}^{*}=a_{c}^{*}=\gamma>0
$$

The stability function is identical to that in Case 1, as given by (21) .

Indeed, without interaction between emissions and adaptation, the tradeoff between the two becomes a non-strategic issue, that is, a given country's adaptation cannot affect the emission strategies of other countries.

Proposition 1 relates to the scenario where $\theta=0$ and shows that adaptation, in this case, does not affect the stable size of IEAs. That is, regardless of the level of adaptation, the stable size is small, in line with the existing literature on IEAs. The next question addressed in the paper is whether this result carries over to the case where $\theta$ is strictly positive. 


\subsection{Case 3: Adaptation with interaction $(\theta>0$ and $\gamma \geq 0)$}

When $\theta>0$, there exists an interaction between emissions and adaptation in the damage function. The scenario where $\theta>0$ and $\gamma \geq 0$ an interesting case arises, which is in contrast to the small coalition puzzle of Cases 1 and 2. First, we show that the sign of the stability function is independent of the values of $\gamma$ and $\omega$ (See Appendix). We then report our results on the stable size of the coalition as $\theta$ varies in Table 1 . Note that Table 1 is valid for all possible combinations of parameters $\gamma$ and $\omega$. We have checked that it is always possible to find combinations of $\gamma$ and $\omega$ such that $e_{s}\left(s^{*}\right), e_{n s}\left(s^{*}\right), a_{s}\left(s^{*}\right)$ and $a_{n s}\left(s^{*}\right)$ are strictly positive for the combinations of $\theta$ and $s^{*}$ that are reported in Table $1 .{ }^{14}$

\begin{tabular}{lllllllllll}
\multicolumn{10}{c}{ Table 1. Stable size, $s^{*}$, as $\theta$ varies $(n=100)$} \\
\hline$\theta$ & 0.01 & 0.02 & 0.05 & 0.2 & 0.3 & 0.4 & 0.5 & 0.6 & 0.7 & 0.8 \\
$s^{*}$ & 3 & 3 & 3 & 6 & 10 & 15 & 21 & 28 & 34 & 41 \\
\hline
\end{tabular}

Proposition 2: The stable coalition size, $s^{*}$, is increasing in $\theta$.

Proposition 2 indicates that an increase in $\theta$, increases the stable size $s^{*}$, as shown in Table 1.

In the existing IEA literature (without adaptation), it is well-established that the freeriding incentives are weaker when the marginal damage from emissions is smaller. This is because countries within the coalition realize that in the cooperative equilibrium they can emit more. Since adaptation reduces the marginal damage from emissions, one might expect that this prevents countries from free-riding which results in larger stable coalition as per Proposition 2. However, this explanation of Proposition 2 would also imply that the emissions of member countries increase as $\theta$ increases. By Lemma 1, this would further imply that global emissions, $E^{*}$, increases as $\theta$ increases. Our next step is to verify if this is necessarily the case in the presence of adaptation.

\footnotetext{
${ }^{14}$ See Table A1 in the Appendix for further details of the ranges of $\gamma$ and $\omega$ for which the non-negativity constraints are satisfied.
} 
Table 2. Stable size, $s^{*}$, global emissions, $E^{*}$, and global welfare, $\mathbf{W}^{*}$, as $\theta$ varies for $n=100, \gamma=1, \omega=60$

\begin{tabular}{llllllll}
$\theta$ & 0.2 & 0.3 & 0.4 & 0.5 & 0.6 & 0.7 & 0.8 \\
$s^{*}$ & 6 & 10 & 15 & 21 & 28 & 34 & 41 \\
$E^{*}$ & 2118.3 & 759.9 & 400.5 & 248.7 & 169.8 & 122.6 & 91.5 \\
$W^{*}$ & $-3.7 \times 10^{6}$ & $-1.9 \times 10^{6}$ & $-1.1 \times 10^{6}$ & $-7.1 \times 10^{5}$ & $-4.9 \times 10^{5}$ & $-3.6 \times 10^{5}$ & $-2.7 \times 10^{5}$ \\
\hline
\end{tabular}

Result 1: For $\theta>0.1$, the equilibrium level of global emissions, $E^{*}$, is decreasing in $\theta$.

Result 1 follows from Table 2. It is important because scientists working on climate change have traditionally held the view that adaptation will lead to greater levels of global emissions, thus increasing the risk of climate change induced catastrophes. Result 1, however, shows that the opposite may occur. That is, adaptation may indirectly reduce the equilibrium level of global emissions by causing larger IEAs to achieve stability.

Moreover, Result 1 shows that the explanation behind Proposition 2 that is provided by the existing literature to explain the positive relationship between free-riding incentives and marginal damage from emissions is not applicable in our model. Our model provides an alternative intuition behind large stable coalitions and low marginal damage from emissions when the low marginal damage is caused by adaptation. This stems from two key features in our framework: (i) emission strategies of countries are strategic complements for $\theta>0$, as shown by Lemma 1; (ii) the signatories act as a Stackelberg leader in the membership game. The latter feature implies that the signatories take into account whilst deciding their own emission strategies that if they increase emissions then so will the non-signatories. Therefore, they have an incentive to emit less compared to the case where $\theta=0$. This, in our model, leads to lower global emissions with coalition formation as long as $\theta>0$, as summarized by Result 1.

Result 2: For $\theta>0.1$, the equilibrium level of global welfare, $W^{*}$, is increasing in $\theta$.

The existing literature on IEAs shows that within the context of membership games 
similar to the one used in this paper, it is ambiguous whether welfare improves as coalitions are formed and enlarged. Hence the importance of Result 2 which shows that in the presence of adaptation, it is possible that larger coalitions do lead to increases in global welfare. The presence of adaptation raises the following question, a priori. Does adaptation, by reducing the damage from emissions, reduce the desirability of larger IEAs from a social welfare perspective? In fact, Result 2 shows that this is not the case. The higher is $\theta$ (i.e. the more effective is adaptation), and the larger is the corresponding size of the stable IEA, the higher the global welfare level.

Although Table 2 illustrates Results 1 and 2 for $\gamma=1$ and $\omega=60$, we have checked that the same result holds qualitatively for several other combinations of $\gamma$ and $\omega .{ }^{15}$ Results 1-2 together show that if countries choose adaptive measures that have a high $\theta$, then the formation of larger stable IEAs is facilitated. Moreover, achieving lower global emissions and higher global welfare becomes more likely than in the absence of adaptation.

Next, we compare the total emissions under coalition formation against the non-cooperative benchmark. Our results are summarized in Table 3, which shows the ranges of $\omega$ for which total emissions falls as a result of the formation of an IEA of size $s^{*}$, i.e. $\Delta E<0$. Note that in Table 3, the ranges of $\omega$ satisfy the non-negativity constraints as summarized in Table A1 in the Appendix. The results are valid for all $\gamma>0 .{ }^{16}$

\footnotetext{
${ }^{15}$ We have chosen to present that case where $\omega=60$ because this satisfies the non-negativity contraints of all quantities for all the different values of $\theta$ considered in Table 2, in line with Table A1 in the Appendix.

${ }^{16}$ See Table A1 in the appendix for further details regarding the parameter values for which all equilibrium quantities are non-negative.
} 


\begin{tabular}{|c|c|c|}
\hline$s^{*}$ & $\theta$ & $\omega$ \\
\hline 3 & 0.05 & $0.2<\omega<1.75$ \\
\hline 6 & 0.2 & $2<\omega<3.75$ \\
\hline 10 & 0.3 & $3<\omega<9$ \\
\hline 15 & 0.4 & $6<\omega<16$ \\
\hline 21 & 0.5 & $12<\omega<25$ \\
\hline 28 & 0.6 & $21<\omega<36$ \\
\hline 34 & 0.7 & $37<\omega<47$ \\
\hline 41 & 0.8 & $57<\omega<63$ \\
\hline
\end{tabular}

Result 3: For $\theta>0$, it is possible to have large stable coalitions that reduce total emissions relative to non-cooperation.

Table 3 shows that when we account for adaptation with $\theta>0$, there exist a range of intermediate values of $\omega$ for which the formation of large stable coalitions reduces total emissions and at the same time satisfies the non-negativity constraints. This result is in contrast to the argument about large coalitions being "shallow", as presented by Barrett (2003) and Finus and Rundshagen (2003). ${ }^{17}$ However, for $\theta>(<) 0.1$ and sufficiently large (small) $\omega$, the change in global emissions due to coalition formation is positive. Indeed, this is a dismal result where a large agreement is stable but does not achieve emission reduction.

\section{Concluding remarks}

According to The Economist (27 November 2010), "the green pressure groups and politicians who have driven the debate on climate change have often been loth to see attention paid to adaptation, on the ground that the more people thought about it, the less motivated they

\footnotetext{
${ }^{17}$ Note that these papers set up repeated games to model the incentives of countries to unilaterally deviate from an IEA. They do not model adaptation.
} 
would be to push ahead with emissions reduction." We show in this paper that adaptation does not necessarily lead to increased emissions. On the contrary, adaptation by countries to climate change may induce the formation of larger stable IEAs which ultimately result in lower global emission and higher global welfare.

Moreover, we show that this positive outcome is more likely to occur the greater the degree to which the adaptive measure reduces marginal damage from emissions. Therefore, it is not only the amount of adaptation undertaken by countries in equilibrium that matters for the stability of IEAs, but also the "type" of adaptation, as captured by our parameter $\theta$. This suggests that when international negotiations are held, it is important for countries to actively cooperate not only on reducing emissions, but also on the type as well as level of adaptive measures to undertake. A priori it is unclear why countries should cooperate on domestic policies to undertake adaptation which only reduce the damage from emissions locally and have no direct effect on the damage suffered by other countries. This paper illustrates that although the direct effect of adaptation may indeed be local, adaptation undertaken by an individual country/region may still have externalities on other countries by indirectly affecting the equilibrium level of global emissions.

In the current paper, we have analyzed the case of identical countries. In reality different regions are vulnerable to different degrees to the effects of climate change and will therefore undertake different amounts/types of adaptation, for example, Southern Europe is expected to be affected more than Northern Europe by climate change. Therefore, allowing for asymmetries across countries would be a useful extension. 


\section{References}

Auerswald, H., Konrad, K., Thum, M., 2011. Adaptation, Mitigation and Risk-Taking in Climate Policy. CESifo Working Paper No. 3320.

Bahn, O., Breton, M., Sbragia, L., Zaccour, G., 2009. Stability of international environmental agreements: an illustration with asymmetric countries. International Transactions in Operational Research, 16, 307-24.

Barrett, S., 1994. Self-enforcing international environmental agreements. Oxford Economic Papers 46, 878-894.

Barrett, S., 2003. Environment \& Statecraft: The Strategy of Environmental TreatyMaking. Oxford University Press, New York.

Bosello, F., 2004. Timing and Size of Adaptation, Mitigation and R\&D Investments in Climate Policy. FEEM Discussion Paper.

Breton, M., Sbragia, L., Zaccour, G., 2010. A Dynamic Model for International Environmental Agreements. Environmental \& Resource Economics, 45, 25-48.

Buob, S., Stephan, G., 2009. To Mitigate or To Adapt: How to combat with climate change. NCCR climate Working Paper 2007/1.

Carraro, C., 2010. Adaptation vs Mitigation in a climate CGE. WCERE

Carraro, C., Siniscalco, D., 1993. Strategies for the international protection of the environment. Journal of Public Economics 52, 309-328.

Chander, P., Tulkens, H., 1995. A core-theoretic solution for the design of cooperative agreements on transfrontier pollution. International Tax and Public Finance 2, 279293.

Chander, P., Tulkens, H., 1997. The core of an economy with multilateral environmental externalities. International Journal of Game Theory 26, 379-401. 
D’Aspremont, C. A., Jacquemin, J., Gabszeweiz, J., Weymark, J. A., 1983. On the stability of collusive price leadership. Canadian Journal of Economics 16, 17-25.

De Bruin, K., Dellink,R., Agrawala, S., 2009. Economic Aspects of Adaptation to Climate Change: Integrated Assessment Modelling of Adaptation Costs and Benefits. OECD Environment Working Paper 6.

De Bruin, K., Dellink,R., Tol, R., 2009. AD-DICE: An implementation of adaptation in the DICE model. Climatic Change, 95, 63-81.

De Cara, S., Rotillon, G., 2001. Multi greenhouse gas international agreements. Mimeo.

Diamantoudi, E., Sartzetzkis, E., 2006. Stable international environmental agreements: An analytical approach. Journal of Public Economic Theory 8, 247-263.

Dutta, P. K., Radner, R., 2004. Self-Enforcing Climate-Change Treaties. Proc. Nat. Adad. Sci. U.S.

Dutta, P. K., Radner, R., 2006a. Population Growth and Technological Change in a Global Warming Model. Economic Theory, pp. 251-270.

Dutta, P. K., Radner, R., 2006b. A game-theoretic approach to global warming. Advances in Mathematical Economics, 8.

Finus, M., Rundshagen, B., 2001. Endogenous coalition formation global pollution control. Working Paper, FEEM, Nota di Lavoro 43.

Finus, M., Rundshagen, B., 2003. Endogenous coalition formation in global pollution control: A partition function approach. In: Carraro,C. (Ed.), Endogenous Formation of Economic Coalitions, E. Elgar, Cheltenham.

Hoel, M., de Zeeuw, A., 2010. Can a focus on breakthrough technologies improve the performance of international environmental agreements? Environmental and Resource Economics 47, 395-406. 
Hoel, M., Schneider, K., 1997. Incentives to participate in an international environmental agreement. Environmental and Resource Economics 9, 153-170.

Ingham, A.,Ma, J., Ulph, A., 2005. Theory and practice of economic analysis of adaptation. Discussion paper, Tyndall Centre for Climate Research.

lo, F., 2004. Timing and Size of Adaptation, Mitigation and R\&D Investments in Climate Policy. FEEM Discussion Paper, Milan.

Kane, S., and G. Yohe, 2000. Societal Adaptation to Climate Variability and Change: An Introduction. Societal Adaptation to Climate Variability and Change, 45, 1-4.

Kane, S., Shogren, J., 2000. Linking Adaptation and Mitigation in Climate Change Policy. Climatic Change, 45, 75-102.

Klein, R., Schipper,E., Dessai,S., 2003. Integrating mitigation and adaptation into climate and development policy: three research questions. Discussion paper, Tyndall Centre for Climate Research.

Klein, R., Schipper,E., Dessai,S., 2005. Integrating mitigation and adaptation into climate and development policy: three research questions. Environmental Science and Policy, 8, 579-588.

Le Goulven, K., 2008. Financing Mechanisms for Adaption. Commission on Climate Change and Development.

Legras, S., Zaccour, G., Temporal flexibility of permit trading : what if pollutants are correlated?, forthcoming in Automatica.

Manne, A. S., Mendelsohn,R.,Richels, R., 1995. A model for evaluating regional and global effects of GHG reduction policies. Energy Policy,23(1), 17-34.

McKibbin, W., Wilcoxen, P., 2003. Climate policy and uncertainty: the roles of adaptation versus mitigation. In Living With Climate Change: Proceedings of a National Conference on Climate Change Impacts and Adaptation. 
Nordhaus, W.,Yang, Z., 1996. A Regional Dynamic General-Equilibrium Model of Alternative Climate-Change Strategies. The American Economic Review, 86, 741-765. Parry, M., Canziani,O., Palutikof, J., van der Linden, P., Hanson, C., 2007. Climate Change 2007: Impacts, Adaptation and Vulnerability. Contribution of Working Group II to the Fourth Assessment Report of the Intergovernmental Panel on Climate Change. Cambridge University Press.

Petrosjan, L., Zaccour, G., 2003. Time-consistent Shapley value allocation of pollution cost reduction. Journal of Economic Dynamics and Control, 27, 381-98.

Ranghieri, F., 2010. Safe and Climate Resilient Cities. World Bank Institute, paper presented at the International Workshop on "The State of International Climate Finance: Is it adequate and is it productive?", organized by the International Center for Climate Governance, held in Venice, October 2010.

Rubio, J. S., Casino, B., 2001. International cooperation in pollution control. Mimeo. Rubio, S.J., Ulph, A., 2006. Self-enforcing international environmental agreements revisited. Oxford Economic Papers, 58, 233-63.

Rubio, S.J., Ulph, A., 2007. An infinite-horizon model of dynamic membership of international environmental agreements. Journal of Environmental Economics and Management, 54(3), 296-310.

Stern, N., 2006. Stern review: the economics of climate change. HM Thresury, London. The Economist. "How to live with climate change:It won't be stopped, but its effects can be made less bad". 27 November 2010.

The Economist. "Adapting to climate change: Facing the consequences". 27 November 2010.

Tol, R., 2005. Adaptation and mitigation: trade-offs in substance and methods. Environmental Science and Policy, 8, 572-578. 
Tulkens, H., Eyckmans, J., 1999. Simulating with RICE Coalitionally Stable Burden Sharing Agreements for the Climate Change Problem. Center for Operations Research and Econometrics Working Paper No. 9926.

de Zeeuw, A., 2008. Dynamic effects on the stability of international environmental agreements. Journal of Environmental Economics and Management, 55 (2), 163-74. 


\section{Appendix}

\section{Equilibrium outcomes under coalition formation}

We have the following equilibrium values of $e_{s}$ and $a_{s}$.

$$
\begin{gathered}
e_{s}=\frac{(s-100)^{2} \theta^{4}-(s-2)(s-100) \theta^{2}+s \gamma \theta+(1-s \omega)}{(s-100)^{2} \theta^{4}+\left(2 s-s^{2}-200\right) \theta^{2}+1} \\
a_{s}=\frac{(s-100)((s-100) \omega+100) \theta^{3}+\gamma\left((s-100) \theta^{2}+1\right)+\left(\left(s-s^{2}-100\right) \omega+100\right) \theta}{(s-100)^{2} \theta^{4}+\left(2 s-s^{2}-200\right) \theta^{2}+1}
\end{gathered}
$$

From $(A 1)$ and the non-signatories' reaction function, as given by (12), we have

$$
e_{n s}=\frac{\gamma \theta-(100-s)\left(s \theta^{4}+\gamma \theta^{3}\right)-\left((s-100) \omega+\left(s^{2}-2 s+100\right)\right) \theta^{2}-(\omega-1)}{(s-100)^{2} \theta^{4}+\left(2 s-s^{2}-200\right) \theta^{2}+1}
$$

From $(A 2)$ and (14), we have

$$
a_{n s}=\frac{(s-100)((s-100) \omega+100) \theta^{3}+(s-100) \gamma \theta^{2}+\left(\left(s-s^{2}-100\right) \omega+100\right) \theta+\gamma}{(s-100)^{2} \theta^{4}+\left(2 s-s^{2}-200\right) \theta^{2}+1}
$$

From $(A 1)$ and (12), the equilibrium global emissions, that is, the sum of emissions of all countries is given by

$$
\begin{aligned}
E & =s e_{s}+(n-s) e_{n s} \\
& =\frac{\left(\begin{array}{c}
100-\omega\left(s^{2}-s+100\right)+\theta \gamma\left(s^{2}-s+100\right) \\
-\gamma(s-100)^{2} \theta^{3}+\theta^{2}(s-100)(s \omega-100 \omega+100)
\end{array}\right)}{(s-100)^{2} \theta^{4}+\left(2 s-s^{2}-200\right) \theta^{2}+1}
\end{aligned}
$$


From $(A 5)$ and $(7)$, we have that the change in global emissions due to coalition formation is given by

$$
\begin{aligned}
& \Delta E=E-100 e_{n c} \\
= & \frac{\left(\theta \gamma-\omega+100 \theta^{2}\right)\left(s \theta^{2}-100 \theta^{2}-s+1\right) s}{\left(s \theta-100 \theta^{2}+s \theta^{2}+1\right)\left(s \theta^{2}-100 \theta^{2}-s \theta+1\right)(10 \theta+1)(10 \theta-1)}
\end{aligned}
$$




\section{Stability function}

$$
\begin{aligned}
& \Phi(\theta, \gamma, \omega, s) \\
& =\frac{1}{2}\left(100 \theta^{2}+\gamma \theta-\omega\right)^{2} \\
& \left(\begin{array}{c}
-s^{2}+4 s-\theta^{4}\left(10809 s^{2}-41212 s-204 s^{3}+s^{4}+20805\right) \\
-\theta^{6}\left(10802 s^{2}-60198 s-204 s^{3}+s^{4}+2009799\right) \\
-\theta^{2}\left(818 s-215 s^{2}+6 s^{3}-s^{4}-608\right) \\
\frac{-\theta^{8}\left(4060200 s-60601 s^{2}+402 s^{3}-s^{4}-102010000\right)-3}{\left(s^{2} \theta^{4}-s^{2} \theta^{2}-200 s \theta^{4}+2 s \theta^{2}+10000 \theta^{4}-200 \theta^{2}+1\right)} \\
\left(s^{2} \theta^{4}-s^{2} \theta^{2}-202 s \theta^{4}+4 s \theta^{2}+10201 \theta^{4}-203 \theta^{2}+1\right)^{2}
\end{array}\right)
\end{aligned}
$$

We note that the sign of the stability function is independent of the parameters $\omega$ and $\gamma$. This follows directly from $(A 7)$. 


\section{Non-negativity constraint}

Table A1: Range of $\omega$ such that non-negativity
\begin{tabular}{llll}
$\theta$ & $s^{*}$ & $\omega$ \\
\hline 0.01 & 3 & $0<\omega<0.5$ \\
0.02 & 3 & $0<\omega<1$ \\
0.05 & 3 & $0<\omega<1.75$ \\
0.2 & 6 & $\omega>2$ \\
0.3 & 10 & $\omega>3$ \\
0.4 & 15 & $\omega>6$ \\
0.5 & 21 & $\omega>12$ \\
0.6 & 28 & $\omega>21$ \\
0.7 & 34 & $\omega>37$ \\
0.8 & 41 & $\omega>57$
\end{tabular}

Table A1 shows the ranges of $\omega$ for which the equilibrium levels of emissions and adaptation in all scenarios are non-negative for all $\gamma>0$. We use these parameter values to generate Tables 1-3. 